\title{
En tiempos de desolación, nunca hacer mudanza: "Escrúpulos de conciencia" y perseverancia jesuita en el Perú del siglo XVII
}

\author{
In time of desolation never to make a change: \\ "Scruples of conscience" and jesuit perseverance in \\ 17th Century Peru.
}

Juan Miguel Dejo Bendezu SJ*

Resumen: El artículo explora casos de nulidad de profesión de votos en la Compañía de Jesús en el siglo XVII peruano. El objetivo es analizar conflictos de la subjetividad que, en el paradigma espiritual de aquel entonces, se interpretaban desde la perspectiva jesuita como "escrúpulos de conciencia". Se describe e interpreta lo ocurrido en cinco jesuitas y el modo en que atravesaron una crisis en su compromiso con la institución. A través del análisis de estos casos presentados en el Tribunal eclesiástico, se intenta reconstruir los entretelones de una experiencia de crisis para observar cómo los mecanismos que San Ignacio denomina tentaciones del mal espíritu afectan y desestabilizan un adecuado discernimiento.

Palabras clave: Escrúpulos de conciencia, crisis, mal espíritu, discernimiento, profesión de votos.

Abstract: The article explores cases of nullity of profession of vows in the Society of Jesus in the Peruvian 17th Century. The aim is to analyze how the conflicts of subjectivity in the spiritual paradigm of that time, were interpreted from the perspective Jesuit as "scruples." The article describes and interprets what happened in five Jesuits and the way they went through a crisis in their commitment to the institution. Through the analysis of these cases presented at the Ecclesiastical Court, the author tries to reconstruct

\footnotetext{
* Doctor y profesor asociado de la Universidad “Antonio Ruiz de Montoya”. Perú.

E-mail: juan.dejo@uarm.pe
}

5 Juan Miguel Dejo Bendezu. En tiempos de desolación, nunca hacer mudanza ... 5-27. 
an experience of crisis to observe how the mechanisms of what St. Ignatius called as temptations of evil spirits affect and disrupt a proper discernment.

Key words: Scruples, Crisis, Evil spirit, Discernment, Profession of vows.

Recibido: 6 de setiembre de 2016

Evaluado: 8 de noviembre de 2016 
Hombres y mujeres del siglo XVII comparten con nosotros el hecho de enfrentar diversas situaciones en la existencia que constituyen obstáculos. Ansiedades, angustias y temores, siguen paralizándonos hoy como ayer. Sin embargo, las mediaciones conceptuales y culturales por medio de las cuales configuramos un sentido tanto de lo que vivimos como de lo que padecemos, han sufrido variaciones.

En el siguiente artículo intentaré hurgar la sensibilidad subyacente en la experiencia espiritual de cinco individuos que durante el siglo XVII solicitaron por diversos motivos, que se le revocasen los "votos" que habían hecho como religiosos en la Compañía de Jesús. Los expedientes revisados nos permiten constatar que las razones que ellos aducen no necesariamente se corresponden con lo que pudieron vivir internamente, ya que ellos recurren al Tribunal Eclesiástico para que éste decida la susodicha nulidad, saliéndose de los límites institucionales de la Compañía de Jesús, en los que estos casos debían tratarse. Así, ellos asumen un discurso jurídico que como es natural, los coloca en una representación de sí mismos que oculta en gran medida las motivaciones subjetivas que sólo podrían comprenderse desde el contexto de la vida religiosa de la época. Las mediaciones conceptuales y culturales que constituían el receptáculo de las experiencias de la sensibilidad, al ser distintas de las de nuestros días, deben ser analizadas desde los paradigmas desde los cuales ellas veían la luz, para así poder comprender mejor el modo en que las personas de otras épocas vivían su subjetividad. En el caso que nos ocupa, es necesario entender un conjunto de variables de interpretación espiritual y religiosa de la época para poder entender realmente qué había detrás del drama que significaba para un religioso con varios años de ejercicio, pedir que se le permitiera renunciar a una vida que en algún momento de su vida, había escogido para siempre.

\section{Ser jesuita en el siglo XVII peruano}

En el siglo XVII la Compañíaa de Jesús llegó a tener en el Perú un promedio de 250 miembros, con diversas fluctuaciones. Durante dicho siglo, el índice del crecimiento de la Orden en el territorio peruano siguió un ritmo sostenido iniciado desde su llegada en 1568. El Virreinato del Perú fue entendido por los jesuitas como un territorio de misión, noción ésta última que se entendía como esencial a la institución fundada por San Ignacio de Loyola. La rápida identificación del término de "misión" con el hecho de desplazarse a zonas alejadas de la cultura europea, llegó a efectuar un desplazamiento en el imaginario espiritual de los mismos jesuitas. Para muchos, ser jesuita de manera eminente, significó ir adonde la fe cristiana aun no había sido llevada, enfrentado riesgos de toda índole, hasta el sacrificio de la propia vida.

Podemos decir entonces que la identidad jesuita en el siglo XVII estaba condicionada por las posibilidades que podía tener el sujeto de ser más o menos útil en los desplazamientos misioneros que se hacían de manera continua, organizados la mayoría de ellos, desde los "colegios". Estos últimos tenían no sólo el prestigio de formar a religiosos, clérigos y laicos, sino que preparaban a los futuros misioneros; en ellos se daban el encuentro distintos grupos de misioneros, los más entrados en años, que, enfermos o cansados se retiraban para dedicarse a tareas menos exigentes así como los que retornaban periódicamente de sus respectivas peregrinaciones; muchos de ellos se dedi-

\footnotetext{
${ }^{1}$ La estrecha relación organizativa que existía entre colegios y misiones la he estudiado en el capítulo 2 de Dejo, 2008; ver también: Maldavsky, 2013.
} 
caban además a la enseñanza de lenguas aborígenes, por entonces requisito para la ordenación sacerdotal en el Perú.

Faltan más estudios sobre el modo en que se vivía en estos colegios. Por los documentos que he podido investigar para este trabajo, podemos tener la impresión que una recia y hasta a veces dura disciplina los regía, pese a que ya desde fines del XVI se denunciase lo "relajado" de las costumbres, en el proceso de adaptación a la realidad colonial que no era del gusto de las autoridades metropolitanas. ¿Es posible pensar que en los casos que estudiaremos a continuación, los jesuitas que se quejan de la dureza de los castigos, respondiese a esta reacción ante los excesos que se podía cometer en una cultura "proclive al desorden"? ${ }^{2}$ Ciertamente esta supuesta dureza no fue la razón para que los jesuitas intentaran anular su profesión como religiosos; pero sí fue uno de los rasgos aducidos por casi todos los que postulan su causa para ser seguida en el Tribunal eclesiástico.

\section{La documentación y su origen jurídico}

De los casos que hemos revisado, cuatro corresponden al Tribunal Eclesiástico llevados por los mismos jesuitas implicados. Dos más se encuentran en el Archivo General de la Nación; uno llevado por la madre de un jesuita, a despecho, probablemente, del conocimiento de su hijo, y con probable disgusto del mismo ${ }^{3}$. El otro es un documento único ya que debió quedar entre la documentación jesuita que llegó a manos del archivo nacional al momento de la expulsión de la orden en 1767: se trata de un recurso legal por el que se otorga la nulidad a un jesuita y que será para nosotros un contrapunto del resto de documentos, ya que en este caso, es el único documento con que contamos en el que se demuestra del modo en que se procedía en estos casos, al interior de la Compañía, y no recurriendo a los tribunales, como es el caso de los anteriores.

Los casos que veremos dan testimonio de que hubo ocasiones en que las motivaciones por las que los jesuitas no pudieron resolver sus conflictos ad intra, les llevaron más lejos, a buscar el modo de dejar la Compañía recurriendo al Tribunal Eclesiástico. ¿Por qué tomaron esa actitud, a sabiendas de que había procedimientos que podían desembocar en la solución del conflicto? ¿Qué hizo que las autoridades jesuitas no pudiesen controlar dichas situaciones? Parte del conflicto reside en el hecho de que la idea de una dimisión era bastante difícil de aceptar.

\footnotetext{
${ }^{2}$ Se puede constatar testimonios de jesuitas a lo largo del siglo XVI que al venir de España se sorprenden de las licencias que se permiten los jesuitas "criollos": en una carta enviada al Padre General Aquaviva, y al evaluar las razones por las cuales pedían que se separase el noviciado del escolasticado, las autoridades jesuitas de la provincia del Perú le decían que uno de los motivos era por ser los nacidos en tierras peruanas "poco profundos, no ahondadores de cosas ni amigos de cavar en espíritu" así como amantes de "curiosidades y novedades y cosas exteriores, someros y superficiales": Carta de la Provincia del Perú al P. Gral. C. Aquaviva, agosto de 1588, Monumenta Peruana (en adelante MP) IV: 403.

${ }^{3}$ Este caso no lo hemos incluido en nuestro análisis por tratarse enteramente de las declaraciones y presiones ejercidas por la madre del joven jesuita. El único dato que recuperamos para el análisis es el que tiene que ver con los castigos dados a los miembros de la orden, punto al que aludo al final del trabajo. Cfr. Compañía de Jesús, AGN, Compañía de Jesús, Legajo 151, Documento 2.
} 


\section{Los $\operatorname{casos}^{4}$}

El primer caso que citaré es el que se halla en un par de folios del Archivo General de la Nación, en Lima. Se trata, sin duda, de un documento que dejó la privacidad de los archivos de los jesuitas una vez que éstos fueran expulsados de los territorios de la Corona. En dicho documento se otorga la nulidad de los votos, simples y profesos ${ }^{5}$, al Padre Diego Marín. Como tal, parece que se trata de un documento que concluye un expediente perdido hasta la fecha. En dicho registro el Visitador y Provincial P. Gonzalo de Lira conceden al Padre Marín la nulidad de los votos, sin abundar en mayor explicación. La causa parece ser bien aceptada: la necesidad económica de la que sufre la madre de Marín.

"declaro y de plano como cosa llana y cierta digo por nulla la tal professión del dicho P. Diego Marín y como a tal no professo, absolviénole como le absuelvo por justas causas de los votos simples que al fin de los dos años del noviciado en nuestra Compañía hizo, según nuestros privilegios y letras apostólicas le despido de la Compañía y embío libre de qualquiera obligación "6.

La única razón es el haber hecho la profesión de cuatro votos habiendo tenido en su conciencia la intención de no hacerla si la situación de su madre no se remediaba. Todos los padres convocados a la consulta convienen en "ser nulla la tal professión en el fuero de la consciencia y la declaración del Padre Diego de Torres Vásquez, por donde consta aver resistido al hazer la dicha profession antes della" 7

El caso muestra con claridad que el asunto se toma como un caso de conciencia, y al existir razones que avalan un conflicto propio de este fuero, se acepta como siendo de naturaleza razonable y justificada. Sin embargo, veremos que en otros casos, esto no procede, ya que no se aceptará como un conflicto de conciencia válido o razonable, sino que -siguiendo la lógica y el lenguaje espiritual- se interpretará como una "interferencia" del "mal espíritu".

La supervivencia de este pequeño documento nos es sumamente valiosa para poder detectar el modo de proceder jesuita en casos como el presente. La diferencia que acabo de establecer entre un conflicto de conciencia y otro que es desestimado como tal, es lo que da pie a la temática de este artículo y que denominamos escrúpulos de conciencia. Este es el elemento diferencial entre el caso que acabamos de ver y los que veremos a continuación. Mientras que los jesuitas que dirimen el caso del Padre Marín consideran que en el fuero interno de su conciencia se da pie a considerar la nulidad de la profesión de sus votos, en los casos que veremos luego, las autoridades jesuitas consideraron que lo que estaba detrás del conflicto de los implicados no era precisamente razonable, o, mejor dicho, que se trataba de un conflicto agudizado por falsas razones,

\footnotetext{
${ }^{4}$ Los cinco casos han sido revisados siguiendo una secuencia cronológica.

${ }^{5} \mathrm{El}$ "profeso de cuatro votos" es la figura institucional del jesuita que ha terminado todo su proceso de formación y a quien se le concedía, de manera secreta su "grado". No todos los jesuitas son profesos; los hay llamados "coadjutores espirituales" (sacerdotes) y coadjutores temporales (hermanos). Aquellos se llaman así pues profesan un cuarto voto, que se agrega a los tres votos simples que todos los jesuitas hacen luego de los dos años de noviciado (pobreza, obediencia y castidad). Dicho voto es de obediencia incondicional al Papa en asuntos de misión universal de la Compañía de Jesús.
}

${ }^{6}$ AGN, S/S 3, documento 12, 2 f., 1626.

${ }^{7}$ Ibíd. f. 2. 
lo que en el imaginario espiritual de los jesuitas se considera una clara "tentación" del mal espíritu, bajo la modalidad de los llamados "escrúpulos de conciencia".

\section{Malos manejos y cargos de conciencia}

El segundo caso es quizá uno de los más extensos y complejos ${ }^{8}$. Se trata de un interesante expediente sobre una causa seguida por el Hermano coadjutor ${ }^{9}$ Juan de Zamudio, quien se había desempeñado como procurador -es decir, como administrador de las cuentas- del colegio San Pablo. La causa que esgrime para poder ser aceptada su solicitud de nulidad de profesión de votos, es sacar a relucir un asesinato que habría cometido él antes de ingresar a la Compañía de Jesús en el año 1630 en Buenos Aires, cuando ejercía el cargo de Sargento Mayor. Salvado entonces por el Obispo del lugar, se habría librado sólo pagando una fianza. Luego hizo su ingreso en la Orden en el año de $1635^{10}$.

La solicitud hasta cierto punto es clara y muy simple: declara haber hecho su ingreso sin confesar toda esta historia precedente, por lo que afirma, "la dicha profesión fue nula". Esto le descalificaría de inmediato para la segunda profesión (últimos votos), que alude sin embargo haberla realizado "meticulosamente". Agrega además que los hizo temiendo los rigores del entonces Padre Provincial, Francisco Lupercio de Zurbano. En otras palabras da a entender que no pudo confesar a medida que pasaba el tiempo, viéndose conminado a profesar. El susodicho P. Zurbano, luego de desempeñar el provincialato (1645-1649), pasó a ser Rector del Colegio San Pablo. Zamudio desea aclarar que se trata de su "enemigo capital", para lo cual presenta testigos que avalan esta acusación. Llega a asegurar que el P. Zurbano "ha procurado en la dicha Compañía hacerme todas las vejaciones y daños que ha podido contra mi reputación y es el que me ha puesto en el estado pressente", por lo que pide que no sea el juez en esta causa y se coloque a otro prelado.

El proceso siguió su curso: al solicitar Zamudio la nulidad de los votos pedía también que se le colocara en algún convento de otra Orden. Consecuentemente, el Tribunal lo envió al Convento de Santo Domingo, aunque bajo la supervisión de los jesuitas del Colegio San Pablo. Ya entre los dominicos, la conducta de Zamudio despertó sospechas. La Compañía de Jesús, representada por el P. Felipe de Paz, recibe la solicitud de Zamudio para poder salir en ocasiones del convento de Santo Domingo con el fin de realizar sus propias diligencias jurídicas. Esto traería consecuencias desafortunadas para los jesuitas ya que Zamudio salía del convento con escándalo de algunos testigos, como el procurador De Paz, quien recuerda que:

"todas las veces que quiere en un coche a la plaza pública desta ciudad y calle de los mercaderes donde oy sabado que se cuentan veinte y quatro del corriente

\footnotetext{
${ }^{8}$ El caso cuenta con tres expedientes, dos de los cuales son voluminosos (haciendo un total de 241 folios) siendo uno de ellos las probanzas mandadas a hacer en Buenos Aires para comprobar la veracidad del homicidio del cual el demandante se autoinculpa (AAL, Órdenes religiosas, Jesuitas, Leg. II, exp. 3, 4 y 6).

${ }^{9}$ Cf. nota al pie de página 20, infra.

${ }^{10}$ La víctima era presentada como Antonio Duarte, portugués, "Sobre lo qual fulminó causa criminal contra mi, Don Francisco de Sespedes, governador de aquel puerto y de alli me vine a Potossi y luego a esta ciudad adonde el año 635 tomé el abito de la Compañía" (AAL, Jesuitas, Leg. II, 3, ff. 3ss.).
} 
a las ocho y media de la mañana lo encontré a cortina abierta hablando con el Ldo. Garcia de Ayala y otras personas del comercio con tanta publicidad que le vi y conoci y lo pudieron ver y conocer todas las personas de la dicha calle causando la nota y escandalo que dexa entender de ver un religioso con avito de la Compañía de Jesús en un coche publicamente en la plaza y calle de mas concurso desta ciudad quando jamas a avido exemplar de semejante accion y mucho mas faltando a la clausura que debe guardar en el dicho convento en conformidad del auto del deposito en que se le manda que la guarde"

Las quejas se siguieron dando por parte de los jesuitas quienes elaboraron un documento con la mediación de Antonio Pérez de Villarroel -a nombre del Colegio San Pablo-, rogando al Tribunal eclesiástico que sólo dejasen salir a Zamudio a pie y acompañado de un jesuita designado para ese fin, y sólo en las horas indicadas para el seguimiento de su causa ${ }^{12}$.

La causa seguida por el Hno. Zamudio termina con la comprobación del homicidio cometido por él en el año 1630, mediante la presentación de una serie de testigos así como de una probanza enviada a hacer al Obispado de Buenos Aires. Desde este lugar se envía el expediente conteniendo las declaraciones de los testigos convocados en Buenos Aires. Mientras que los testimonios de los testigos que cita la parte de Zamudio son determinantes, el único testigo presentado por los jesuitas manifiesta debilidad en su declaración ${ }^{13}$. En este punto, llama la atención la insistencia de los jesuitas por negar la posibilidad de que el homicidio cometido por Zamudio haya sido real. ¿A qué puede deberse este empecinamiento de las autoridades jesuitas por tratar de "exculpar" a Zamudio del susodicho homicidio? La respuesta que podría ser obvia es que ellos intentaban negarle la nulidad en la profesión de sus votos. Pero si todo parecía incriminar a Zamudio en tal pasado oscuro y a todas luces, con carácter excluyente de la condición de religioso, ¿por qué la aparente terquedad en no sacarlo de sus filas? ¿Acaso debemos pensar que enterados tardíamente de su condición homicida, ellos querrían "tomar la justicia en sus manos"? ¿No existe otra posibilidad de comprensión de lo que sucedía detrás de estos hechos? Veamos algunos entretelones más de este caso.

Los jesuitas se sienten sorprendidos de que durante el tiempo en que Zamudio había estado en la Compañía de Jesús (un total de veinticinco años):

"nunca dixo tener impedimento para profesar (...) y no parece que con el escrúpulo de un impedimento esencial como lo es de el homicidio prosiguiese tanto tiempo ratificando los votos cada seis meses y haciendo funciones que no son permitidas a quien no tiene certidumbre de que no es religioso, obligando a que los Prelados le encomendasen lo que nunca fuera lícito encargarle si los informara de la verdad como era justo $" 14$.

\footnotetext{
${ }^{11}$ AAL, Jesuitas, Leg. 2, Exp. 4: f. 58; El Procurador, P. Felipe de Paz presenta además dos testigos que presenciaron lo que él declara: ff. 59-63.

12 Ibid: f. 64.

${ }^{13}$ El testigo es un franciscano quien reduce todo su testimonio a decir que de haber sido cierto dicho homicidio, debería haberse enterado de ello porque...era portugués como lo había sido la víctima Antonio Duarte: AAL, Jesuitas, Leg. 2, Exp. 4.

${ }^{14}$ AAL, Jesuitas, Leg. 2, Exp. 4., f. 24. Es costumbre que antes de los últimos votos, los jesuitas candidatos deben renovar sus votos simples hechos al haber finalizado el noviciado de dos años. Zamudio pues,
}

11 Juan Miguel Dejo Bendezu. En tiempos de desolación, nunca hacer mudanza ... 5-27. 
Argumento que hace pasar a los religiosos a otra fase: el Procurador, P. Paz, pide que no se considere el recurso de nulidad que interpone Zamudio, "por ser como es inverosímil el impedimento de que se vale después de tantos años sin que aia (sic) estado jamás indicado del homicidio que se imputa" "15. En el fondo, desea validar el estado de religioso amparado en el hecho de que durante veinticinco años, nunca manifestó escrúpulo alguno al respecto. Pues -entonces se pregunta- ¿cómo alegando lo que alega, se le ocurrió aceptar el oficio de Procurador y Administrador de las rentas del Colegio de San Pablo? Es en este momento que los jesuitas se ven obligados a declarar algo que no había sido manifestado hasta ese momento.

Paz observa que en su desempeño como Administrador de las rentas del Colegio San Pablo, Zamudio siempre afirmó no omitir partida alguna y sólo llegó a hacerlo precisamente al momento en que él plantea la nulidad de su profesión

"ha salido una escritura de dies mil pesos de a ocho reales que parece averla otorgado el dicho hermano Juan de Zamudio como procurador de dicho colegio ante Marcelo Antonio de Figueroa, en favor de Doña Antonia de Lugones, viuda de Don Fernando de Abellaneda"16.

Reclama así cómo en el dicho libro de las partidas del colegio, Zamudio no colocó esa cuenta y que por lo tanto, su deber era declarar toda la verdad. Agrega que en la Visita del Visitador Andrés de Rada, había asegurado que:

"no devía más el dicho colegio que lo declarado en dichas quentas y que era así que tenía el dicho hermano Juan de Zamudio dependencias proprias en que se avia mesclado, que montaban veinte y dos mil ochocientas y ochenta pesos, los quales el dicho hermano avia de satisfacer, y en esta conformidad hizo con deve y ha de aver el descuento expresando lo que también le devían diferentes personas, y tenía destinado para la paga de dichos veinte y dos mil ochocientos ochenta pesos (...) de manera que aseguró al dicho Reverendo Padre Visitador que al dicho colegio no podían pedir más cantidades que las que montan las deudas escritas en dicho libro, porque los dichos veinte mil ochocientos pesos eran de quenta diferente de personas que quisieron valerse de la diligencia y cuidado del dicho hermano Juan de Zamudio",17.

Netamente vamos esclareciendo el entuerto. Todo parece indicar que Zamudio había hecho malos manejos económicos siendo el Administrador del colegio de San Pablo que se descubrieron en el momento en que le hicieron declarar sobre el movimiento de las cuentas realizadas en dicho colegio. Al problema económico se suma el hecho de que Zamudio había ejecutado una serie de decisiones sin tener en cuenta la opinión de sus superiores. Por ejemplo, al recibir un préstamo de Doña Antonia de Lugones, no colocó este monto, como debía haberlo hecho, bajo el rubro de deuda en el libro de cuentas que existía para este fin, sino que al imaginar que tal cantidad de dinero era susceptible de entrar en las arcas en un futuro no lejano, decidió no anotar dicha

debió renovarlos cada seis meses, como dice la declaración. Cfr. Constituciones de la Compañía de Jesús: $346 ; 544$.

${ }^{15}$ AAL, Jesuitas, Leg. 2, Exp. 4., f. 24.

${ }^{16}$ Ibid, f. $24 \mathrm{v}$.

${ }^{17}$ Ibid, f. 25. 
suma en los libros como deuda. Zamudio utilizó más bien otro recurso: al ser nombrado albacea y testamentario de un dinero que había heredado al colegio Don Damián Carrillo, utilizó parte de esta fortuna para pagar la deuda y sus réditos a la susodicha Doña Antonia ${ }^{18}$.

La historia hasta este momento puede parecer más o menos comprensible. Se trataría de un modo de administrar particular, aunque claro está, riesgoso. Todo hubiese pasado desapercibido si las cuentas no hubiesen arrojado déficit. Pero no fue así. El escribano Marcelo de Figueroa en un traslado de las cuentas del colegio de San Pablo que corresponden al período en el que Zamudio fue procurador, manifiesta la total ineficiencia de este último para el cargo, concluyéndose que al dejarlo, Zamudio había endeudado al colegio San Pablo por un monto de 510,385 pesos y 1 real. Cantidad exorbitante que equivaldría en nuestros días a un valor aproximado de poco más de 2 millones de dólares. El documento que testimonia la mala administración de Zamudio, se encuentra firmado por el mismo Rector del colegio San Pablo, el Padre Jerónimo Pallas. No extraña que éste declarase que había de "estinguir este mal estilo de quenta o deuda del procurador para que nunca mas la aya"19.

Si esto era sabido por los jesuitas al momento en que Zamudio pide su nulidad de profesión, ¿por qué no lo denunciaron? Evidentemente porque no era el centro de su atención. Dicho de otro modo: las autoridades jesuitas no estaban preocupadas por el desfalco que había hecho el dicho Hermano durante su administración, sino por el hecho que dejase la Compañía por ese motivo. Por su parte él refuerza su estrategia aduciendo su pasado homicida para obtener la nulidad. Así, la estrategia de Zamudio por medio de su representante, Miguel de Medina, es que todo este asunto de las cuentas del Colegio San Pablo no es sino un pretexto para la dilación del caso, ya que no tendría que ver directamente con lo que estaba en juego, advirtiendo además a los jueces eclesiásticos que su competencia era exclusivamente en relación a la nulidad de la profesión de $\operatorname{votos}^{20}$.

El Padre Felipe de Paz, por su parte, alega que, contrariamente a la opinión de Zamudio, el alegato presentado sobre las deudas contraídas por el antiguo administrador del Colegio de San Pablo "es artículo incidente en el pleito principal" puesto que al saberlas, se evita el perjuicio que se hubiese generado para la Orden jesuita de haberse callado. Paz parece manifestar un giro en la actitud de los jesuitas en este caso, al decir que:

"no es justo que quiera suspender en perjuicio del colegio y comunidad, cuios bienes administró la obligación, que incurrió como religioso, teniendo la culpa

\footnotetext{
${ }^{18}$ Lo testado por Don Damián ascendía a 25,400 pesos de los que Zamudio hizo una serie de compras sobre todo para fines de objetos litúrgicos pues, dice, "su ánimo fue siempre ayudar y favorecer al dicho colegio y no gravarle como lo dicen las partidas de suso referidas". Uno de esos pagos fue a Doña Antonia de Lugones. AAL, Jesuitas, Leg. II, Exp. 4: ff. 78-80.

${ }^{19}$ Ibid, f. 30 .

${ }^{20} \mathrm{El}$ argumento esgrimido por la parte de Zamudio, y que evitaba mostrar las cuentas era en base a la necesidad de dividir los fueros eclesiástico y civil de modo que el eclesiástico dirima sólo la cuestión de la nulidad de votos sin tener en cuenta estos precedentes. Y aunque los jueces se declararon en contra de la separación de fueros y se dio la aclaración de las cuentas, el objetivo de Zamudio prácticamente estaba ya decidido; a la falta de honestidad al haber hecho los votos se sumaría la de su desempeño en el oficio de administrador. Ibid, f. 68.
} 
de aver callado el impedimento que aora manifiesta sí es cierto, y que el colegio y los prelados que procedieron con buena fee no sean restituidos primero",21.

Para avalar la justeza de su solicitud, Paz recuerda que la facultad del Concilio de Trento en estos casos reposa también sobre "la averiguación de la buena o mala fee con que se procedio en el ingreso y en la profesion para muchos effectos". Todo parece indicar que en este momento, la parte jesuita se encuentra ya resuelta a permitir la nulidad de la profesión de votos de Zamudio, una vez que éste ha confesado la malversación de los fondos. En efecto, el expediente concluye con la concesión de la nulidad luego de haber pasado este clímax del proceso judicial.

En este primer caso, llama ante todo la atención la resistencia de las autoridades jesuitas a dejar que Zamudio obtuviese la nulidad de la profesión de sus votos con la confesión de haber cometido homicidio antes de haber entrado a la Compañía. Mediante esta revelación, probablemente hecha ante su superior antes de haber recurrido a los Tribunales, Zamudio pretendía lograr su objetivo de dejar la Orden antes que se descubriesen sus malos manejos. Una vez que esto último se hizo inevitable, recurre a los Tribunales para obtener su final dimisión. Según la declaración del Padre Felipe de Paz, Zamudio no había declarado toda la verdad de los hechos ante sus superiores, ya que sólo:

"aora después de dicha demanda de nulidad de la profesión ha salido una escritura de dies mil pesos de a ocho reales que parece averla otorgado el dicho hermano Juan de Zamudio como procurador de dicho colegio ante Marcelo Antonio de Figueroa, en favor de Doña Antonia de Lugones, viuda de Don Fernando de Abellaneda",22.

Cuando esta noticia sale a la luz se comienzan a desvelar los entretelones de la estrategia de Zamudio. Antes que ello sucediera, debemos más bien imaginar la extrañeza de sus compañeros jesuitas ante su solicitud de nulidad y la súbita evocación de su pasado homicida, que ante ellos aparecería como la manifestación de fuertes escrúpulos al aducir que, al no haberlo confesado en su momento, su profesión religiosa era nula. Es aquí donde centro el tenor de mi interpretación: las autoridades que estaban a cargo de Zamudio no aceptan esta solicitud, ya que la consideran una falsa auto-acusación. Pero no por la sospecha de que hubiese algo detrás de ella, es decir, no porque imaginasen una supuesta "mentira" o "falsedad" como consecuencia de una fallida conducta moral. Lo más probable es que los jesuitas, entendieron que Zamudio se encontraba bajo los tormentos propios del mal espíritu. gresión.

Para entender de qué cosa estoy hablando, permítaseme ahora una pequeña di-

\section{Los tormentos del mal espíritu}

Mientras que en nuestros días la reflexión moral emana exclusivamente de principios normativos que rigen el contrato social, en el siglo XVII la moralidad estaba además asociada a la dimensión intersubjetiva que se presuponía, existía entre Dios y cada uno de los seres humanos. El "bien" era entendido -para los jesuitas, "buen espíritu"- como la presencia concreta y activa de Dios en cada uno. Pero en determinadas

\footnotetext{
${ }^{21}$ Ibid, f. 32.

${ }^{22}$ Ibid, f. 24v.
} 
circunstancias, podía producirse una "ausencia" de Dios. Ésta podía darse a causa del alejamiento del sujeto de sus prácticas devotas o también como una "prueba" para que él mismo se diese cuenta que sin la presencia divina, sus propias fuerzas no eran suficientes para lograr el bienestar espiritual. Esta preceptiva parte de los Ejercicios Espirituales de San Ignacio, en donde se induce al sujeto a hacerse consciente de que una vida de paz espiritual sólo es posible por la gracia de $\operatorname{Dios}^{23}$.

Ahora bien, los estados contrarios a la presencia de Dios (cuyo signo es la paz), producen en el sujeto ansiedad, turbación, confusión, al punto de originarle alteraciones conductuales que, de no ser bien procesadas, lo llevan a "caer en tentaciones". Esos "ataques" de confusión o de ansiedad, se traducen en ideas de culpabilidad, donde el individuo se siente incapaz de ser perdonado, a tal punto que no puede dejar de pensar en su "condena". En otras palabras, se siente acosado por ideas obsesivas y de carácter auto-destructivo. La frontera con lo que hoy en día llamamos "trastornos" ansiosos u obsesivo-compulsivos es evidente. En aquellos tiempos, los jesuitas entendían que la causa debía siempre atribuirse al mal espíritu.

\section{Entre el mal espíritu y la mala conciencia}

Volvamos entonces a nuestro personaje. Si seguimos la explicación que acabamos de dar, los jesuitas habrían entendido que Zamudio estaba acosado por el mal espíritu y que lo que vivía era producto de un estado del alma que San Ignacio llama desolación $^{24}$. En dichos momentos, la teoría sugiere que quien se encuentra en tal estado, no debe hacer ningún cambio respecto a decisiones tomadas de antemano; máxime si se trata de decisiones acerca del "estado de vida" como puede ser las que tienen que ver con la vocación (la frase "nunca hacer mudanza" refiere este precepto) ${ }^{25}$.

Presumo que los jesuitas entendieron que Zamudio se encontraba perturbado por el recuerdo de su pasado homicida y que, atormentado por algo que sus superiores consideraban que era un sentimiento de culpa -a su vez, producto de una "tentación del mal espíritu"-, consideraban que debían dejar pasar ese momento difícil para que Zamudio pudiese reencontrar la paz. Sin embargo Zamudio toma la iniciativa de dejar la Compañía antes de que se descubriese su malversación y como sucede en otros casos que veremos luego, recurre al Tribunal Eclesiástico sin que sus superiores lo supiesen.

La pregunta que surge aquí es si realmente Zamudio se encontraba acosado por una conciencia culposa como producto de un estado espiritual de desolación o si, simplemente, estaba huyendo de una situación que se le hacía insostenible. Probablemente las dos cosas iban de la mano. Pero lo que aparecía ante sus superiores, era un sujeto que se encontraba atormentado y por lo tanto, bajo el riesgo de tomar decisiones de las cuales podía luego arrepentirse.

Llama por eso la atención que el argumento del homicidio no hubiese sido del todo convincente para las autoridades de la Compañía. A este respecto podemos pensar dos posibilidades: o éstas pensaban que era una artimaña de la mente, impulsada por el

\footnotetext{
${ }^{23}$ Véanse las llamadas Reglas de Primera Semana, de los Ejercicios Espirituales, [313 a 327, esp. la 322]. Véase: San Ignacio de Loyola, 1991.

${ }^{24}$ Ibid, [317].

${ }^{25}$ Ibid, [318].
} 
mal espíritu para atormentar fantasmáticamente a Zamudio o en efecto, sí creían que era cierto, pero no le daban el peso suficiente para justificar la salida del estado religioso, basándose en el testimonio de más de 25 años en que como jesuita había hecho anualmente la renovación de sus votos. Sea como fuere, hasta este punto, los jesuitas no quieren dar su brazo a torcer y tratan por todos los medios de que el argumento del homicidio sea desestimado. Pero no fue así.

Probablemente sorprendidos al ver que en efecto, Zamudio había cometido un homicidio, lo que más les dejó estupefactos fue el hecho de que recién 25 años después y bajo las circunstancias del desfalco, Zamudio pidiese la nulidad de sus votos. Y es aquí donde seguramente aparecieron las dudas acerca de si se trataba de un "mal espíritu" circunstancial o si... el espíritu de Zamudio ya había venido a la Compañía con tendencias poco santas.

¿Qué vivió Zamudio en estos momentos de su vida, luego de haberse producido la malversación de los fondos? ¿Es verdad que los malos manejos correspondían a una ineficacia administrativa? ¿O estuvo en la Compañía durante todo este tiempo esperando el momento de poder hacer de las suyas? Si realmente tenía una conciencia recta, ¿por qué nunca mencionó el caso del homicidio y por qué esperó hasta ese momento crítico para esgrimirlo como arma defensiva? ¿Zamudio realmente tuvo escrúpulos de conciencia, acosado por el "mal espíritu" o simplemente lo tuvo todo calculado?

\section{Escrúpulos mayores}

El caso del Padre Antonio de Puga es más revelador de la dinámica de los escrúpulos de conciencia. Varios años después de haber hecho sus votos simples ${ }^{26}$ en la Compañía de Jesús, aparece temiendo que no sean válidos ya que descubre, para su asombro, que al momento de hacerlos no tenía la edad mínima prescrita (17 años). Al dirigirse a las autoridades jesuitas, éstas -según el testimonio de Puga- le dan permiso para ir a Santiago de Chile, a averiguar datos sobre la fecha de su nacimiento. En el ínterin, estando en Potosí, cuando se le solicita hacer su profesión solemne de votos ${ }^{27}$, Puga rechaza hacerla aduciendo que sus primeros votos simples los había hecho a una edad indebida. Para este efecto, envía una carta al Provincial informándole su parecer de que no quería hacer la dicha profesión "respecto de que estaba enterado que no era religioso por no aver tenido edad suficiente al tiempo de su entrada en la religión y al tiempo en que hiço los votos simples"; sin embargo, aceptaba que:

"la profesión la haría el día siguiente solo por cumplir con lo público de la religión, sin ánimo de profesar y por justo temor que tenía de alguna vejación que le hiciese el P. Rector Cristóbal Lizero, conocido y temido en la Provincia por su condición y por lo que con otros súbditos suios avia obrado y que el juramento que avia de hacer ante el dicho Retor a quien temia lo haría con la abstracción conveniente",28.

\footnotetext{
${ }^{26}$ Ver nota 5, supra.

${ }^{27}$ Ibidem.

${ }^{28}$ AAL, Jesuitas, Legajo II, exp. 15, ff. 28-29.
} 
Con probable temor de que la carta de Puga llegase a su destino, dos de los padres que vivían allí, Martín de Jáuregui y Antonio Urbina interceptan un par de copias que había escrito el joven sacerdote con este parecer y en consecuencia, obstaculizan el conocimiento de la situación al provincial. Entonces, la pregunta que surge es ¿por qué interceptaron dichas cartas? Por su parte, Puga, en medio del proceso, reclama que sean exhibidas y dar así cuenta de lo ocurrido, y demostrando que al momento de realizar su profesión de votos, no se hallaba en la disposición de hacerla. A esto se suma que Puga menciona haber sentido presiones para efectuar los votos.

La respuesta por parte de las autoridades jesuitas no se deja esperar; Salvador Apelo, contesta de manera rotunda que la profesión ha de considerarse válida ya que los recursos interpuestos por Puga -aduciendo violencia o presiones de todo tipo-, son infundadas, ya que:

"el único (recurso) de que se vale, que es el miedo, con que dize la hizo (la profesión) se excluye lo primero (...) porque en la religión de la Compañía se procede con tanta atención que jamás se ha violentado a sujeto alguno para que professe contra su Voluntad; antes por parte de los religiosos se solicita con instancias y se tiene por favor y se les concede con toda brevedad y con qualquier pretexto que proponga si se les difiere todo el tiempo de que necessitan como aconteció al P. Antonio de Bolibar que por cierta disposicion de bienes que representó, tenía que comunicar con el Consejero mayor D. Joseph de Bolibar del orden de Santiago su Padre, se le retardó por seis meses y la del Padre Juan de Vicuña por tres, o quatro años; y la del P. Gaspar Gavriel de los tres votos, diez años, por aver propuesto que tenía un negocio pendiente con el Reverendísimo Padre General con que nunca pudo ser motivo ajustado para constituyr el acto involuntario la dicha carta ${ }^{29}$ pues en ella no se le ponía apremio alguno y con qualquiera escusa se pudiera transferir (la fecha de los votos solemnes) ${ }^{30}$.

El documento se extiende, negando incluso la nulidad bajo el pretexto de haber hecho los votos antes de la edad requerida, reduciendo este supuesto error (cosa que además Apello niega ser razón fundada) pues cualquier defecto en estos casos -dice-, quedaba subsanado por las renovaciones anuales que se hacen de los votos simples. ${ }^{31}$

En el proceso todo parece indicar que Puga no llega a hallar razones realmente suficientes como para que su solicitud de nulidad de profesión de votos sea aceptada.

\footnotetext{
${ }^{29}$ Que aducía haber enviado al provincial y haber sido interceptada con lo que el Prov. no había podido enterarse.

${ }^{30}$ AAL, Jesuitas, Legajo II, exp. 15, ff. 30.

${ }^{31}$ Amparándose además en los decretos de la Octava Congregación General, Cf. Ibid, ff- 30-30v. Resultado de su viaje hecho a Santiago, Puga había retornado con la certificación de haber nacido en una fecha posterior a la que se pensaba, con lo que en efecto, sus escrúpulos, aparecían como fundados. Pero a nivel de la jurisdicción propia de la Compañía el argumento hallado es igualmente dirimente: los votos del llamado "bienio" es decir, luego de los dos años de noviciado, tienen valor jurídico. Por último, todos los años se renuevan hasta dos veces (cfr. Supra, nota 14) por lo que de haber habido alguna falla inconsciente, de hecho- en su admisión a una edad más temprana de la pensada, ella se borraba por la participación constante en dichas ceremonias de renovación de votos. En el Archivo General de la Nación existen pláticas (o sermones) dadas en ocasión de la ceremonia de renovación de votos en algunas comunidades jesuitas del Perú; en ellas se hace el elogio de las mismas, así como de su necesidad, habida cuenta de la débil naturaleza humana que olvida el "fervor primero": AGN, Compañía de Jesús, Legajo 62, docs. 1 y 4 .
} 
Por ello, las cartas escritas por Puga e interceptadas por los Padres Urbina y Jáuregui quedan hasta cierto punto invalidadas, al mostrar sólo los escrúpulos de conciencia de Puga en una situación que en consecuencia, era remediable. En el proceso judicial que se sigue, se solicita que se presenten más documentos, dos de los cuales son sendas cartas enviadas por el P. Martín de Jáuregui (futuro provincial en los años 80) a Antonio de Puga. Una de ellas resulta críptica, pues en ella se lee algo que de primera impresión, deja muchas ambigüedades. La parte jesuita por lo tanto, se adelanta a recusar este testimonio aduciendo que en dicha carta trata "de otro sujeto" y no de Puga.

He aquí un momento más de intriga en este proceso. En dicha carta escrita por Jáuregui a Puga, aquel se refiere a un tercer personaje que, acosado por un "escrúpulo mal fundado" le había escrito a su vez una carta que Jáuregui confiesa haber preferido guardar:

"rezele que esse Personaje en carta que escribio en este Chasque, bolvía a repetir la materia de sus escrúpulos: luego que vino el chasque recogi la carta de que embiara téngola guardada en mi poder, cerrada como llegó, que la otra llegó abierta y espero el beneplácito de essa persona para que se rasguen tales cartas, que si llegaran a manos de las personas a quienes se remitían presumieran lo que no le estuviera bien a la honra y buena fama del contenido. Por la sangre de Jesucristo que se me embie licencia para romper tales papeles quiere $V R$ a essa persona y dígale que si estima en algo mi vida, no me de pesadumbre que me mate y afrente, pues su infamia me cogerá de lleno. Consumido vivo después que tengo tales noticias y que serán las más impensadas y escandalosas que se avian visto en la Provincia albentis circumstantiis de la calidad de la persona, juicio, prudencia, buen nombre con que hasta aqui ha vivido. Si mis razones no fueren admitidas sirvase VR derogar a esse sujeto, que si bolviere a escrevir en la materia, no me complique, citándose a cartas que yo he recogido ${ }^{, 32}$.

Creo que a todas luces se trata de una carta semi-cifrada en la que la tercera persona a la que se alude no es otra que Puga; claro que luego, Salvador Apello dirá a nombre de la Compañía de Jesús que en dicha carta no hay nada "que comprehenda a la parte contraria y lo que de ellos se infiere es de otro sujeto y persona distinta con que siempre subsiste el juramento que hiço (Puga)", ${ }^{33}$ No obstante, el testimonio de Jáuregui mismo se contradice con lo que pretende negar Apello, al declarar que había interceptado las cartas enviadas por Puga al provincial pues "sería de nota y escándalo que un sugeto de la virtud y prendas del dicho Don Antonio de Puga digese de nulidad de los votos simples y de la profesión y persistiese en no quedar en la religión" ${ }^{34}$. Esta es prácticamente la misma razón que se alude en aquella carta que recibida por Puga, iba supuestamente con referencias a otra persona que no era él.

De ser cierto que en la carta escrita por Jáuregui a Puga se refería a éste y su intención de dejar la Compañía, ¿por qué Apello lo niega? Obviamente de ser así, es porque se intenta seguir validando sus votos y así denodadamente evitar que el sujeto deje la Compañía. Nuevamente tenemos actitudes similares a las vistas en otros casos. ¿Cuál

\footnotetext{
${ }^{32}$ AAL, Jesuitas, Legajo II, exp. 15, f. 63.

${ }^{33}$ Ibid, f. 69.

${ }^{34}$ Ibid, f. 51.
} 
sería la razón por la que las autoridades jesuitas tratan de evitar el retiro de la Orden de uno de los suyos, aún y cuando podría tener razones sustentables?

La respuesta está en la misma carta que estamos considerando como semicifrada, en la que las razones esgrimidas por P. Martín de Jáuregui son las que aclaran el panorama: se trata de escrúpulos, es decir, de un proceso espiritual en el que el sujeto está prácticamente "fuera de sí".

\section{Escrúpulos irrefrenables}

Lo cierto es que la susodicha carta respondía a una voluntad de ayudar a Puga a que cambiase de opinión y renunciara a su deseo de que anulasen sus votos como profeso. De hecho, el autor de dicha carta, Martín de Jáuregui, declara luego que al pedir ayuda al Provincial para que lo sosegase, recibió como consejo por parte de éste que a su vez le escribiese a Puga, para aconsejarle y calmarle. Aunque no lo diga, es obvio que la carta motivo de disputa, sí se refería directamente a la situación de Puga, aunque Jáuregui optara por un lenguaje semi-cifrado, quizá para evitar que, al caer en manos extrañas (cosa que ocurría con frecuencia con los correos de la época) perjudicara al involucrado.

Hasta este momento en la lectura del expediente uno se puede preguntar si la actitud de Puga no responde sino a terribles y exagerados escrúpulos de conciencia que sus dos compañeros trataban de eliminar, toda vez que la intercepción de las cartas obedecía a que temían que su compañero de religión, hiciese algo de lo cual hubiese podido arrepentirse después. En su justificación de por qué habían interceptado las cartas que Puga había dirigido al Provincial dándole cuenta de su intención de dejar la Orden, tanto Jáuregui como Urbina atestiguan que Puga era una persona proba. Entonces ¿por qué no pensar por un lado, que él realmente creía en sus argumentos y de otro lado que lo que estaba atravesando era una seria crisis existencial manifestada en escrúpulos de conciencia?

Por ello la reacción de los otros dos jesuitas fue protegerlo; el P. Urbina, por ejemplo, que confiesa ser primo hermano suyo, en la probanza que se realiza a petición de la parte de Puga, menciona que le dijo a éste que "se sosegase" para que no dejase la religión, para proteger así su honor. ${ }^{35}$ Lo mismo menciona del P. Jáuregui quien dice, había escrito repetidas cartas instándole a que no dejase la Compañía, "moviéndole a esto el zelo del bien de su alma, 36 .

El testimonio de quien fuese provincial al momento de estos acontecimientos, el P. Luis de Contreras, agrega algunos matices a este caso. Contreras había respondido a Puga que "se sosegase i no se inquietase" y que si el motivo de su desasosiego era que fuese él (Contreras) el provincial, recordase que su gobierno no sería igualmente eterno. Recuerda además que Puga fue a Santiago diciendo que iba a aprender la lengua de los naturales que había aprendido de niño, así como para ver a su madre, a quien la traería a Lima, pero no dijo nada respecto a la pesquisa que debía hacer sobre su edad. Hay un dato que desafortunadamente, queda aislado; el anterior provincial testifica que Puga

\footnotetext{
${ }^{35}$ Ibid, f. 52.

${ }^{36}$ Ibid, f. 53.
} 
fue recluido en el Cuzco por motivos que no llega a explicar ${ }^{37}$. Algo más interesante aún es que en la llamada "consulta" del provincial, se le llegó a otorgar una patente de la nulidad de los votos simples, pero que no tenía efecto en la de la profesión de los votos profesos. Luego de esta declaración, los motivos de Puga para insistir sobre la nulidad de su profesión terminan por aparecer como más inexplicables. Todo podría indicar que en el consejo del provincial, se consideraron como comprensibles los escrúpulos de $\mathrm{Pu}$ ga, y por ello el otorgamiento de la nulidad de la profesión de los votos simples. Sin embargo, aquí surge una aparente contradicción. Por qué, habiéndole otorgado una licencia de los votos simples, insistían sin embargo en que se hiciese caso omiso a su solicitud de nulidad de profesión de últimos votos? ${ }^{38}$ ¿Qué tipo de subterfugio jurídico jesuítico permitía que un sujeto al que se le anulaban los votos simples, pudiese seguir considerándose plenamente jesuita? ${ }^{39}$

La figura de este caso a mi entender, refleja por un lado la interpretación que da la Compañía de Jesús de aquello que sucede en el fuero interno de uno de sus súbditos: Antonio de Puga está aquejado, precisamente antes de pronunciar sus votos como profeso, de terribles escrúpulos de conciencia. Sin poder vencerlos, sus compañeros jesuitas recurren a todos los medios para que sus trámites lleguen al fin, que en este caso, consideran sería a todas luces, errático. No obstante, Puga, empecinado, lleva el caso a los tribunales y en ese camino, las cosas se ponen cada vez más difíciles. Si lo que querían intentar tanto el Provincial como sus hermanos de religión, era el escándalo, éste ya había estallado, y el caso siguió ante los Tribunales por un tiempo más. ${ }^{40}$

\section{Dudas y temores}

Los últimos dos casos que veremos, son de dos jóvenes jesuitas que acababan de hacer los llamados votos simples o del "bienio" (en alusión a los dos años de noviciado que se hacen previamente). El primer caso es protagonizado por el Hno. Joseph de Mere, quien solicita que se le dé la nulidad de dichos votos, aduciendo que antes de que los hiciese, solicitó a sus padres retornar a la casa familiar, sin respuesta favorable por parte de ellos. Obligado por la presión de estas circunstancias, había realizado los votos. Pese a ello un tiempo después, solicitó la nulidad. Como en anteriores ocasiones, al final de su solicitud, menciona que sea colocado temporalmente en otro lugar, "por temerme

\footnotetext{
${ }^{37}$ Según la declaración de Puga, la reclusión en el Cuzco habría sido para desmotivarlo de su viaje a Santiago para averiguar su verdadera edad.

${ }^{38}$ Ibid, ff. 55-56.

${ }^{39}$ Una figura igualmente sorprendente es la que denuncia la parte de Puga, quien revela que el P. Jáuregui le aconsejó que hiciese revalidación de sus votos en secreto. A estas alturas del análisis, podemos afirmar que la pretensión de Jáuregui era intentar que Puga olvidase la idea de dejar la Orden, ya que con toda probabilidad, opinaba, como el resto de sus compañeros, que lo que debía hacerse era calmar los escrúpulos de Puga de una manera práctica y definitiva. Puga sin embargo, lo entendería como una manera desviada de silenciarlo (Ibid, ff.56-57).

${ }^{40}$ Lo cierto es que el proceso sigue su curso y los jueces fallan en contra de la solicitud de nulidad de profesión que ha pedido Puga, a lo cual sigue toda una recusación de dicho fallo por parte del mismo Puga. Los tonos siguen subiendo, llevando a Puga a reclamar que uno de los jueces, el Provisor Joseph Dávila Falcón, por haber sido enemigo de miembros de su familia, mostrándose en "el mal afecto y poca voluntad con que a visto mis causas", dando razón la enemistad entre dicho Provisor y el Dr. D Fernando de Cartagena, "opositor que fue con dicho Provisor a la cátedra de prima de Cánones", (Ibid, f. 80) siendo los hermanos de Puga compadres de Elvira de Cartagena, hermana del Dr. Cartagena.
} 
justamente me an de aser muchas molestias $i$ vejaciones pendiente este pleito por aora y en el inter",41.

En el espacio de esta primera declaración y el que sigue al inicio del proceso, el Hno. Mere debió reconsiderar la situación, pues el expediente concluye casi de inmediato con una declaración del susodicho, mencionando:

"que con menos deliberación y sin tener los fundamentos que eran necesarios para la dicha nulidad la deduje en juicio y aora movido de mi conciencia y reconociendo aver hecho legitimamente los dichos votos en la forma que mejor proceda de derecho me desisto y aparto de la dicha demanda para no seguirla aora ni en tiempo alguno (...) pido se me imponga perpetuo silencio respeto de aver sido siniestra su relación y convenir assi a la seguridad de mi conciencia lo qual sera justicia que pido,"42.

Si seguimos la lógica de nuestros casos anteriores, en esta ocasión, el Hno. Mere, aquejado por escrúpulos de conciencia, cuyas razones escaparán para siempre de nuestro registro, encontró sin embargo condiciones de poder reconsiderar la situación, vencerlos y así retornar sin mayor dilación al curso de la vida que había escogido.

El caso del Hno. Jacinto Gómez de los Ríos es un poco más complicado. Jacinto se presenta para la nulidad de su profesión de votos simples aduciendo que había entrado al noviciado por temor de su padre y con la esperanza de retornar a Tierra Firme (Nueva Granada), cosa que sin embargo, pasados dos años (momento de hacer los votos simples) no había podido llegar a hacer. Desesperanzado, Jacinto le cuenta la verdad a su Padre, pidiéndole no hacer los votos y dejar la Compañía. Encolerizado, el capitán Gómez de los Ríos le amenaza ya que:

"en caso que pussiesse en effecto lo que proponía, me avia de matar o echarme a Baldivia (Chile), y horrorizado de dicha comminación por la summa aspereza de la condición de dicho mi Padre, a que me assistían multiplicadas experiencias hize los votos primeros en dicho noviciado". ${ }^{3}$

Como hemos visto en los casos anteriores, recurrir al Tribunal eclesiástico despierta los temores del Hno. Gómez de los Ríos, por lo que solicita ser cambiado temporalmente, mientras dure el juicio a otro convento, ya que "por aver propuesto los fundamentos que llevo expressados a los Prelados me trataron con toda aspereza". "Consecuentemente el Licenciado Don Lucas de Segura y Lara, Provisor y Vicario General del Arzobispado, manda que se le traslade al convento de San Francisco ${ }^{45}$ conminándole a no salir excepto para los trámites del juicio que iría a comenzar. ${ }^{46}$

\footnotetext{
${ }^{41}$ AAL, Órdenes religiosas, Jesuitas, Leg. III, Exp. 1: ff.1-2.

${ }^{42}$ Ibid, f. 4.

${ }^{43}$ AAL, Ordenes religiosas, Jesuitas, Leg. III, Exp. 15, f.1.

${ }^{44}$ Ibid, f.1.

${ }^{45}$ Habiendo solicitado de antemano la copia de la fórmula de los votos del noviciado: Ibid, f.2.

${ }^{46}$ Llama la atención la disposición de que le señalen compañero con quien salir y que "no pueda salir solo ni a mula"; véase el caso de Juan de Zamudio, -uno de los primeros casos de nulidad de profesión de que se guarda registro- en el que precisamente un motivo de molestia para los jesuitas fue el que Zamudio saliera sin cargo de conciencia, en mula, siendo así que llamaba la atención en religiosos que eran muy
} 
Ante la actitud tomada por el Hno. Jacinto Gómez de los Ríos, las autoridades jesuitas reaccionan con un documento muy interesante en donde dejan nota de su modo de proceder: contesta el P. Juan de Goicochea, Procurador de la Provincia peruana manifestando que no debe aceptarse el recurso de enviar al susodicho Hno. Gómez al convento de los franciscanos pues el Hno. Gómez "dio principio a su inquietud extrayendo sus libros y papeles de dicho colegio con ánimo de haser fuga, y para cohonestarla publicó que no era religiosso". Más aún, según refiere el P. Goicochea, en lugar de manifestar "la tentasión que padesía, para que le encomendassen a su divina Majestad" y contando con fundamentos, el Hno. Gómez podría haber logrado la susodicha "relaxacion de votos conforme a los privilegios de nuestra religión”. Sin embargo, no procedió adecuadamente: comunicó a algunas personas de fuera de la Orden que iba a plantear la nulidad de sus votos, más allá del claustro mismo, hasta llegar a solicitar a un seglar que le ayudase en la testificación del Tribunal eclesiástico. Ante estas confusiones que a todas luces debió causar el Hno. Gómez en el colegio de San Pablo,

"se le mandó retirar a una celda donde se le puso cama desente sin pricion que otro apremio más que el de dicho retiro para evitar la fuga, y el Padre Ministro de dicho Colegio de San Pablo le amonestó caritativamente y le mandó ayunar uno u dos biernes, y que por si tomasse una u dos diciplinas (y no más) y con esta diligencia sin haver precedido otra lo qual juró in verbo saserdotis executó dicho Hermano Jacinto su ausencia echándose por las paredes y ocultándose hasta el día de oy". ${ }^{7}$

De allí los temores que surgen en el Hno. Gómez de las represalias que habrían de tomar los religiosos con él de seguir adelante con sus planes. Para el P. Goicochea quien realmente se excedió fue:

"dicho Hermano, pues quebrantó el depósito y la clausura sin caussa lexitima, que no lo pudo ser la de correxirle como a hijo con la blandura referida, y cometió despojo de sí mismo constituyéndosse en voluntaria apostasia sin nesesidad urgente". 48

El grave error del Hno. Gómez, de acuerdo al testimonio del P. Goicochea es que no comunicó a sus superiores, aquello que estaba sucediendo en el fuero de su conciencia: sus temores, las probables débiles razones con las que había ingresado a la vida religiosa, etc. Este silencio agravó aún más su propia situación espiritual. Entrado en desesperación, y ante el temor de la represalia paterna, se vio entre la espada y la pared. En su conciencia atormentada por temores probablemente infundados, se veía entre el castigo en la casa paterna o en el colegio jesuita. Pero lo que da cuenta del "modo de proceder jesuita" y la concreta definición del "estado del alma" del Hno Gómez, es la solicitud del P. Goicochea; éste solicita que no se le envíe a convento alguno, sino que se le remita de nuevo al colegio San Pablo, donde, dice, lo tendrían "sin apremio ni castigo mientras se difine esta caussa, y cessan los escrúpulos que afecta para mantenerse en el dicho despojo." 49

observantes en el cuidado de su imagen pública. Al Hno. Gómez se le amenaza con la excomunión mayor latae sententiae: Ibid, f. 3.

\footnotetext{
${ }^{47}$ Ibid, f. 4

${ }^{48}$ Ibid, f. $4 \mathrm{v}$.

${ }^{49}$ Ibid, f. 5.
} 
El expediente concluye prácticamente aquí, con un documento más ${ }^{50}$ en el que se da el poder de llevar adelante esta causa en nombre de la Compañía, al P. Andrés Pardo, en representación del P. Juan Yáñez, Rector del Colegio Máximo San Pablo, y Vice Provincial de la Compañía de Jesús en el Perú. ¿Qué sucedió luego? Obviamente no hubo proceso. Lo más probable es que Jacinto Gómez de los Ríos regresara al Colegio San Pablo y que se resolviese la situación ad intra, como sucedió en el caso del Hno. Mere, aunque la inexistencia de una declaración similar a la que culminó el proceso de este último, puede levantar algunas sospechas.

\section{Rastreando conciencias y perturbaciones espirituales de otros tiempos}

En los casos que hemos reseñado, en todos ellos, hay algunos indicios de "síntomas" similares. Para poder intentar un análisis desde un punto de vista de la historia de la espiritualidad, permítaseme revisar algunas variables que han sido ya anunciadas a lo largo de este artículo y que pienso ahora profundizar.

En primer lugar se trata de individuos que han escogido un estado de vida que para la época era realmente determinante. Para quien vive en el siglo XXI y se ha acostumbrado a entender que los compromisos de carácter personal son hasta cierta medida relativos y que los mismos se subordinan a un principio de "libertad" de elección de los estados de vida en que uno se sitúa, cuesta trabajo entender que un compromiso de for$m a$ de vida podía ser pensado como irrenunciable. Todos los casos revisados deben partir de este presupuesto: los jesuitas viven al interior de un universo mental en que la decisión por la vida religiosa implicaba una imposibilidad de renunciar a dicho estado.

En segundo lugar, todos recurren al Tribunal eclesiástico como el único recurso de poder obtener la nulidad de la profesión de votos. Este rasgo va de la mano con la evidencia de que este tipo de conflictos debían resolverse siempre al interior de la institución jesuita, y no fuera de ella.

En tercer lugar en todos los casos la actitud de las autoridades jesuitas es insistir en el retorno de los que buscan la nulidad, tratando por todos los medios de que sean disuadidos de su intención. Paralelamente, todos éstos manifiestan un temor de represalias de los jesuitas hacia ellos.

En lo que sigue formularé la hipótesis que ya he deslizado con anterioridad y que a mi juicio explica lo que está aquí en juego: los jesuitas que piden la nulidad de su profesión de votos, son en principio "aquejados" por un "mal" de carácter espiritual y que en el lenguaje jesuítico de la época (y de hoy, en sentido espiritual) se denomina escrúpulos. Originados por un curso de pensamientos con el carácter por lo general de dudas, miedos o razonamientos inquisitivos $-\mathrm{y}$ que pese a que puedan presentarse bajo una estructura lógica- terminan por convertirse en pensamientos obsesivos que perturban la conciencia y la paz del individuo, hasta el punto de llevarlos a dudar de los "pilares" en que reposa su propia existencia, uno de ellos, su identidad vocacional y religiosa. Mi impresión es que en todos los casos que hemos encontrado se da testimonio de los escrúpulos de conciencia que aquejaron a algunos religiosos jesuitas y que a través del modo en que se dieron los diferentes procesos a nivel jurídico eclesiástico, podemos profundizar en la manera en que se percibían los conflictos psicológico-

\footnotetext{
${ }^{50}$ Ibid, f. 6.
} 
espirituales de la época así como las "políticas" de administración de la vida espiritual de los individuos que pertenecían a una institución religiosa así como el modo cómo ésta los entendió y procesó, dándole un sentido a una sintomatología que fue siempre interpretada como "espiritual". Bajo el lente de esta hipótesis intentaré sistematizar el análisis de los casos reseñados.

\section{La conciencia y sus escrúpulos}

La palabra escrúpulo viene del latín scrupulus, que significa pequeña piedra. Bajo la figura de un guijarro en el zapato que no deja caminar, los "escrúpulos de conciencia" refieren la idea de una conciencia que se encuentra obstaculizada de su "fluir natural". En el caso del imaginario jesuita del siglo XVII, el tema era bastante conocido pues sus orígenes se encuentran con la misma experiencia vivida por su santo fundador. Para San Ignacio, el tema de los escrúpulos es fundamental y le dedica un apartado en sus Ejercicios espirituales.

"llaman vulgarmente escrúpulo, el que procede de nuestro propio juicio y libertad, es a saber, quando yo líberamente formo ser peccado lo que no es peccado; así como acaece que alguno después que a pisado una cruz de paja incidenter, forma con su propio juicio que a pecado; y éste es propiamente juicio erróneo y no proprio escrúpulo". 51

Se trata pues de un error de juicio, en otras palabras, de un error ocurrido en el (dis)curso del pensar. San Ignacio mismo lo había vivido en su propio proceso espiritual, previo a la fundación de la Compañía de Jesús. No mucho tiempo después de haber pasado por un cambio radical en su vida, por el cual dejó de lado la vida de cortesano a la que estaba destinado, se dirigió a Montserrat a hacer confesión de toda su vida pasada; pero dirigiéndose luego a Manresa, fue de pronto "a tener muchos trabajos de escrúpulos", que no eran sino un curso de pensamientos que le atormentaban respecto de si había confesado realmente "absolutamente todos" sus pecados.

"perseveraba en sus siete horas de oración de rodillas, levantándose a media noche continuamente, y en todos los más ejercicios ya dichos; mas en todos ellos no hallaba ningún remedio para sus escrúpulos, siendo pasados muchos meses que le atormentaban (...) Estando en estos pensamientos, le venían muchas veces tentaciones con grande ímpetu para echarse de un agujero grande que aquella su cámara tenía, y estaba junto del lugar donde hacía oración. Mas conociendo que era pecado matarse, tornaba a gritar: "Señor, no haré cosa que te ofenda»; replicando estas palabras, así como las primeras, muchas veces ". 52

Esta es básicamente la estructura desde la que se entiende en la espiritualidad ignaciana el síntoma en que se presentan los escrúpulos de conciencia. El sujeto es atormentado por la idea de haber cometido un grave error, por el que no puede encontrar la paz, ya que no se siente "perdonado". El síntoma, que en nuestros días asociaríamos, como veré al final, con pensamientos obsesivos que inducen (o que son inducidos por) estados de ansiedad o de angustia, no permiten que el razonamiento lleve a salir de este

\footnotetext{
${ }^{51}$ Ejercicios Espirituales, San Ignacio de Loyola 1991, n. 346.

${ }^{52}$ Autobiografía de San Ignacio de Loyola, [22, 24 y 25]: San Ignacio de Loyola, 1991: 115-117.
} 
estado, sino todo lo contrario; su naturaleza es repetitiva, circular, y los pensamientos pueden remontarse al infinito en una escalada de mayores dudas, cada vez más minuciosas y autodestructivas.

En el caso de Juan de Zamudio, he mencionado que los documentos no muestran con claridad los motivos de su impulsivo deseo de dejar la vida religiosa. No obstante, se puede deducir que si ello se produjo luego de haber cometido graves errores en su administración y si, según lo comprobado el dinero que fue motivo de su malversación no tuvo otros fines que el gasto para la propia Orden (aún y cuando esto no queda del todo esclarecido) ciertamente puede pensarse que lo que Zamudio se vio "atacado" por escrúpulos venidos del pasado, razón por la cual consideraba que las razones por las que había entrado a la Compañía de Jesús no eran correctas. Ello nos haría entender por qué los jesuitas insisten en no considerar la razón esgrimida (haber cometido un asesinato en el pasado) como válida para su dimisión ya que probablemente, interpretaban que la solicitud de Zamudio venía de los escrúpulos de una conciencia "desolada" y que en ese caso, "no debía hacerse mudanza" hasta que el espíritu se encontrase en paz.

No obstante, el proceso ulterior parecería mostrar que Zamudio no se encontraba necesariamente en desolación, sino que simplemente, había vivido su pertenencia a la orden jesuita de modo bastante superficial. Me atrevería a pensar que uno de los detonadores fue el momento en que lo vieron ser conducido en un coche por las calles, con actitudes netamente mundanas. Ello, agregado a las declaraciones sobre los gastos realizados de manera fraudulenta en el Colegio de San Pablo, levantaron sospechas sobre el carácter espiritual de Zamudio, hasta desvelarse que se había aprovechado durante todos esos años, de quienes hasta entonces lo consideraban uno de ellos.

En el Caso del P. Antonio de Puga se nota con claridad cómo una simple idea llega a convertirse en obsesión escrupulosa y que, aquejando la conciencia, hace sentir al individuo estar en falta. Un error podría haber sido que al permitirle viajar para comprobar los datos que confirmarían si había hechos sus votos simples en una edad anterior a la permitida, no se hizo sino aumentar su ansiedad y en consecuencia dar la razón a los escrúpulos que le atormentaban con la culpa. Desde entonces Puga no halló más la paz. Se sintió cada vez más víctima de ese error y todo le llevó a actuar de acuerdo a lo que podría parecer "lo más correcto": solicitar su nulidad de profesión. Desde un punto de vista ético, nada cuestionable. Pero desde otra perspectiva, los jesuitas observaron este caso como un conflicto espiritual. Yendo más allá de una lógica rigurosa que juzga los hechos a partir de una suerte de "legalidad", los jesuitas vieron en la angustia de Puga una clara manifestación de escrúpulos de conciencia que por el "mal espíritu" buscaban que el sujeto dejase la Orden. Esta convicción clarifica la actitud de los jesuitas que hacen todo lo posible porque Puga se apaciguara y siguiese su vida en paz. Sin embargo, la crisis de ansiedad por la que atraviesa Puga parecía no acabar pues su obsesión le condujo a buscar pretextos de tipo jurídico para avalar su posición. La documentación aquí se detiene y no sabemos cuál fue su destino posterior.

En los casos de los Hnos. Mere y Gómez, se trata de dos jóvenes jesuitas, aún sin votos profesos y "escolásticos" es decir, aun no ordenados como sacerdotes. Ambos han hecho los votos del bienio y a todas luces, se dejan llevar por el apresuramiento. Aun quizá no acostumbrados a las prácticas de discernimiento de jesuitas con más años de formación, ambos actúan precipitadamente, aquejados por temores y ansiedades que les llevan a "perder el juicio espiritual" y terminar tomando decisiones de las cuales se 
arrepentirían. En el caso de Mere, el arrepentimiento es escrito. En el caso de Gómez, deducimos que se dio luego de su retorno al Colegio San Pablo.

\section{A modo de colofón}

Si bien debemos reconocer que la ciencia contemporánea nos ha dado mayores luces para entender la conducta humana y sus disfunciones a través de la historia, no deja tampoco de ser legítimo preguntarse si todas las perturbaciones psíquicas puedan explicarse desde el mismo ángulo de observación que hoy entendemos como psicológico. Es cierto que la misma conceptualización de la herramienta de la "psicología" ha puesto un nombre a una dimensión que no estaba del todo clara en el pasado. En esta línea los casos que hemos analizado en este artículo pueden ser útiles para entender la psicología de aquellos que vivían en colectivos asociados a regulaciones de orden religioso. Nos ayuda a entender también que aquello que se tematizaba en el pasado como escrúpulos de conciencia, no está disociado, en la experiencia personal del sujeto, de intrincados mecanismos fisio-psicológicos ni de la trama histórica de los procesos de socialización vividos por él. En otras palabras, hoy estaríamos más aptos para entender mejor (y superarlos, en consecuencia) los procesos obsesivos-compulsivos ligados a la experiencia religiosa y espiritual.

Mi interés a través de este artículo tiene que ver también con lo que intento traer a colación con estos últimos párrafos: no podemos pensar que las epistemologías contemporáneas por el hecho de pertenecer a los paradigmas de consenso científico reciente, deban tener más legitimidad o alcance que las del pasado. De hecho, así como hoy por hoy hemos comenzado a reconocer cada vez más el peso del saber de las culturas que convenimos en llamar "originarias" respecto, de por ejemplo, la relación con la naturaleza, también podríamos recuperar la valoración por lecturas de la existencia basadas en herramientas de la vieja espiritualidad.

Desde ellas se entendía la humanidad no como un conjunto de mónadas potencialmente autárquicas, susceptibles de ser observadas desde aparatos más o menos eficientes para predecir conductas, sino como entidades en relación unas con otras y sobre todo, con una Trascendencia que a su vez, era protagonista de un escenario existencial que se concebía como el de un "combate espiritual". Desde este teatro de la existencia, los sujetos encontraban la paz y la plenitud en la medida en que se hallaban más o menos cerca de la Trascendencia. Así, los escrúpulos de conciencia -o trastornos obsesivos, como quiera que se les llame- podían ser un signo del sujeto para saber cuán cerca o cuán lejos se encontraba de un equilibrio espiritual que entonces, determinaba el equilibro psíquico. La vida religiosa, pródiga en rituales y ejercicios diversos, era también un espacio terapéutico en la medida que otorgaba a los diversos colectivos de una sociedad un conjunto de pautas que podían "dirigirle" en pos de una plenitud. Que este camino estuviese también interferido de confusiones o malas interpretaciones, no es nada que deba sorprendernos. Que la estructura de comprensión de la realidad basada en un Relato en el que la Trascendencia que vela por su "creación" generase instancias superyoicas con cargas de ansiedad en los individuos hasta generar obsesiones no es necesariamente la responsabilidad del Relato, sino de algo propio de la limitada naturaleza humana para poder existir de una manera enteramente libre o desligada de conflictos. Podríamos quizá imaginar que la superación histórica de estos modelos del pasado mediante nuevos Relatos que interpretan la existencia de modo absolutamente inmanente, debería haber ayudado también a superar esas obsesiones culposas del pasado cristiano. 
Sin embargo, todos sabemos que en realidad, aun si los escrúpulos de conciencia parecerían haberse diluido en una sociedad que como la contemporánea, propugna cierto desenfado ante la moral individual, no por ello se han desvanecido con la misma fuerza los trastornos obsesivo-compulsivos. Todo lo contrario, no sólo subsisten sino que viven bajo disfraces de la misma manera en la que en el pasado, el hábito cubría las ansiedades del monje. En conclusión, ayer, como hoy, los temores infundados, la inseguridad respecto a las decisiones fundamentales del sujeto, los pensamientos oscuros que quitan la paz, eran también parte de la existencia humana. Sólo que se "trataban" de una manera distinta a la que se hace hoy en día. En ese sentido, la divisa de en tiempos de desolación no hacer mudanza, no es sólo un recuerdo retórico. A fin de cuentas, frente a aquellos pensamientos que aun con apariencia lógica clara y distinta, amenazan con desviarnos de rumbo inútilmente, hoy como ayer, no deja de ser una sabia advertencia de sentido común.

\section{Archivos citados}

AGN. Archivo General de la Nación, Lima, Perú.

AAL. Archivo Arzobispal de Lima, Perú.

\section{Bibliografía}

Coello, Alexandre (2006). Espacios de exclusión, espacios de poder, Lima: PUC-IEP.

De Certeau, Michel (1982). La Fable Mystique. Paris: Gallimard.

Dejo SJ, Juan (2008). "La Mística de la acción de los primeros jesuitas en el Perú: Introducción a una historia de la espiritualidad colonial". Tesis de Maestría, Lima, PUC.

Egaña SJ, Antonio de (1954-1974). Monumenta Peruana (1565-1599). 6 Vol. Roma: Institum Historicum Societatis Iesu.

Maldavsky, Aliosha (2013). Vocaciones inciertas. Misión y misioneros en la provincia jesuita del Perú en los siglos XVI y XVII. Lima: UARM-IFEA.

Martín, Luis (1968). The Intellectual Conquest of Peru. The Jesuit College of San Pablo, 1568-1767. New York: Fordham University.

Pallas SJ, Gerónimo (2006 [1621]). Mission a las Indias. De Roma a Lima: La "Misión a las Indias", 1619 (Razón y visión de una peregrinación sin retorno). Madrid: Consejo Superior de Investigaciones Científicas.

San Ignacio de Loyola (1991). Obras completas. Madrid: BAC.

Vargas Ugarte, Rubén (1941). Los jesuitas del Perú, 1568-1767. Lima. s/e 